\title{
A Systemic Review of Incidence of Cancer and Challenges to its Treatment in Nigeria
}

Njaka SRN*

Ebonyi State University, Nursing Science, Presco Campus Abaki Ebonyi State, Abakaliki, Nigeria

\begin{abstract}
This study systematically reviewed the incidence of cancer and the challenges to its treatment in Nigeria. Critical and in depth review of the studies available on the condition was done with the aim of identifying the status of cancer in Nigeria and challenges to treatment. The basic finding was that Nigeria has been under the bondage of cancer with little or nothing being done by both Nigerian government and international agencies to alleviate the suffering. The most current data on cancer was in 2012 and revealed that newly diagnosed cases of cancer in Nigeria per year was at 102000 people while 71,000 died from cancers. This presented Nigeria at the fore front of African countries with cancer cases. Since 2012 till date no data is available on the status of cancer in Nigeria. The studies further revealed the challenges facing cancer care to include the following: poor health system, lack of human resource, lack of screening centers, cost of drug. In conclusion, cancer cases are in a pandemic level in Nigeria evidenced by uncountable people who died of it daily. Nigeria health system is ill equipped to withstand the situation coupled with her current dilapidated economic state. Further studies should be carried out in the different geopolitical zones as to obtain a comprehensive data on the status of cancer in Nigeria.
\end{abstract}

Keywords: Cancer; Incidence; Challenges and treatment

\section{Introduction}

Cancer has been variously defined by different researchers but according to world health organization cancer is defined as a group of diseases that involve abnormal cellular growth which is capable of metastasis [1]. However not all cancers possess the ability to metastasize to other locations in the body via lymph or blood. Cancers could be in various types such as cervical, ovarian, breast, lung, cancer of the blood, and prostate cancers and many others. It is causing great havoc in our country and killing our people in folds of thousands per year. It is very sad that quite a good number of Nigerians out there are suffering from clinical features of the disease or another and have no idea that it is the disease that is gradually destroying their lives. The incidence and damaging effect of cancer in our country Nigeria cannot be overestimated. It is overwhelming and rapidly increasing in numbers and the mortality rate not left out [2]. According to Hajia Yaradua, the scourge of cancer and its destructive effects have been a recurrent decimal and a good number of families in Nigeria has shared the pain of premature death of members resulting from cancer.

A good number of prominent and internationally recognized citizens of Nigeria had died mysteriously because of cancer because there was no screening and diagnostic centers available for early detection or that cancer treatment centers are in none existence in the country. Only very few of them could be recalled and are as follows Mr. Yinka Craig, Mrs. Alarere Alaibe, Mr. Sonny Okosuns, Ms. Tyna Onwudiwe Oputa and others. The above examples are being remembered simply because they had held prominent position in the country and outside the country but the big question remains, what about the uncountable Nigerians who were not prominent and could not afford the least form of cancer treatment? Hajiya yaradua [3].

The above incidence led the First Lady Hajiya Turai Yarâ Adua to come up with the initiative to establish the first dedicated International Cancer Center in Nigeria and West Africa in 2009 located in Abuja. The center was to be an internationally recognized center fully equipped and professionally staffed. It was to be wholly comprehensive and committed to promoting excellence in cancer related care (diagnosis and treatment), cancer prevention, cancer education, training and research (vanguard news). But the truth remains that the state of the hospital is currently nothing to write home that's why Nigerians who could afford cancer treatment rapidly travel out of the country for oversea treatment on noticing any form of cancer changes [4].

According to vanguard news 2009, data from the World Health Organisation shows that 17 million new cases diagnosed per year will increase to an estimated 25 million cases per year by 2015. Nigeria with its population of 100 million in 1992 had an estimated 100,000 new cases per year. With the current population at 140 million (2006 census), it is expected that new cases would rise to about 500,000 per year by 2015 .

\section{Incidence of cancer in Nigeria (earlier data)}

The earliest study from Nigeria on cancer was from the Ibadan cancer registry 1960-1969, there was higher rate of cancer in females with age standardized rates of 105.1 per 100,000 females and 78 per 100,000 male Edington and Maclean. In 1978,74.5 and 65.9 per 100,000 female and males respectively. In Zaria registry 1976-1978, 1575 cases were reported with $52 \%$ in females and $48 \%$ in males.

\section{Twenty first century cancer incidence in Nigeria}

2001-2005, data from Ibadan registry shows that there is an increasing incidence of cancer at 81.6 and 115.1 per100000 male and

*Corresponding author: Njaka SRN, Ebonyi State University, Nursing Science, Presco Campus Abaki Ebonyi State, Abakaliki, Ebonyi 53, Nigeria, Tel: +2347031060479; E-mail: degreatstan@gmail.com

Received October 13, 2016; Accepted December 12, 2016; Published December 15 2016

Citation: Njaka SRN (2016) A Systemic Review of Incidence of Cancer and Challenges to its Treatment in Nigeria. J Cancer Sci Ther 8: 286288. doi: 10.4172/1948-5956.1000429

Copyright: @ 2016 Njaka SRN. This is an open-access article distributed under the terms of the Creative Commons Attribution License, which permits unrestricted use, distribution, and reproduction in any medium, provided the original author and source are credited. 
female respectively. 1n 1999-2004 at Kano registry, a total of 1001 new cases of cancer were recorded with male accounting for $50.3 \%$ while female accounted for $49.7 \%$ of the cases. Jos registry was not left out as in 1995-2002, 1162 and 1657 new cases were recorded respectively for both male and female patients with cancer of all types. Data from university of Benin teaching hospital shows that 2258 new cases were recorded in two years' interval with female predominating while Calabar data shows that in 2004-2006, 588 new cases of cancer were recorded with male dominating with $50.9 \%$ while females had $49 \%$.

According to Oxford journal, annals of oncology, there were 12.4 million new cases of cancer and 7.6 million cancer related death worldwide, more than $2 / 3$ of which occurred in developing countries especially African. Nigeria account for more than 50\% of the 681000 new cases of cancer reported in Africa despite lack of data on the cancer status of most regions in Nigeria. In 2011, 200,000 new cases of cancer in Nigeria were revealed.

It was therefore projected that by the year $2030,70 \%$ of new cases of cancers will be found in developing countries mainly African countries with Nigeria at the fore front possibly because of its population and poor health system.

According to WHO, cancer incidence in Nigeria was estimated at 90.7 and 100.9 per 10000 persons for male and female while the death rate was at72.2 and 76 respectively. This is extremely high compared to the cancer incidence in Ghana which was at 89.1 and 104.1 per 100,000. From the above findings, it is obvious that some regions of the country Nigeria have no national cancer registry or that it is not functional hence absence of data on cancer status of those regions. This is very bad and detrimental to the health of the individuals living in such regions.

In 2012, the following information was revealed about cancer in Nigeria: Population of Nigeria was $166.6 \mathrm{~m}$, newly diagnosed cases of cancer were 102000, and people that died from cancer were 71,600. This is outrageous and calls for global intervention. This simply reflects that nothing reasonable has been done in Nigeria regarding cancer diagnosis, treatment and even prevention (global CAN 2012). Between 2012 till present no data is available on the status of cancer simply because of lack of registry centers in the country or nonfunctional state of the few that exist because they are not equipped and staffed.

\section{Challenges of cancer treatment}

The threat posed by cancer and cancer related diseases is increasingly becoming bigger problem in developing countries than human immunodeficiency virus (HIV)/acquired immunodeficiency syndrome (AIDS). The burden of cancer related health challenges in developing countries is currently approaching pandemic proportions. More than half of the 12.4 million estimated new cases of cancer in 2008 worldwide and two-thirds of the estimated 7.6 million cancer deaths occurred in developing countries [5].

Worldwide, good number of people died of cancer and cancer related causes each year compared to the number of death resulting from AIDS, tuberculosis, and malaria altogether and it is still on the increase. Health care system of many developing countries which are ill equipped are presently struggling to contain the HIV/AIDS epidemic hence very handicapped in dealing with the present situation and challenges posed by cancer (American cancer society).

According to Ngoma, Cancer remains a low priority for low and middle income countries health spending and donor nations and agencies. It is only about $5 \%$ of global resources devoted to cancer are spent in developing countries and cancer control is conspicuously absent from the internationally agreed millennium development goals [6].

In Nigeria cancer is often being perceived as end to one's life simply because of series of reasons including poorly equipped hospitals, lack of knowledge on the part of the people, lack of trained oncology human resource, lack of drugs and high cost of treatment, limited screening centers, government's poor attitude towards policy formulation and implementation [7].

\section{Lack of screening centers}

Screening for early signs of neoplastic changes is one of the major ways of preventing and detecting cancers in its earliest stages as to avert the devastating dangers of cancer. Some types of cancers especially cervical cancer can generally be prevented through vaccination and screening and treatment of early lesion which might lead to neoplastic changes. Most forms of cancers have good outcome if detected on time through screening tests. This is the core aim of establishing screening centers in different parts of the countries but it is quite unfortunate that in most developing countries including Nigeria there is only one or two cancer screening centers located only in the capital cities if any. Access to diagnostic services for cancers is limited to few private hospitals (world cancer declaration)

\section{Diagnostic technique}

Lack of diagnostic facilities is one of the major challenges of cancer treatment in developing countries including Nigeria. Mammography and other radiological and non-radiological examination are very essential diagnostic technique for cancer. Availability of well-trained oncology and non-oncology staff are part of cancer preparedness plan of any country that has interest in cancer care. According to oxford journal of oncology, the above diagnostic and treatment resources are scarce and nonexistent in most Asian and African countries.one of the factors affecting the prognosis of cancer in both developed and developing countries of the world is early detection. According to annals oxford journal of oncology, a pilot program in Malaysia succeeded in reducing the number of breast cancers presented in stages 3 and 4 from $77 \%$ to $37 \%$ as a result of community public awareness campaigns and the training of health staff in clinical cancer examination thereby pinpointing the relevance of staff training in the diagnosis and treatment of cancer. It was reported that in developing countries cancer diagnostic and therapeutic facilities, trained manpower among others are still inadequate to meet the needs of the populations. Whereas there are about four radiotherapy machines per million population in UK and 8.0 machines per million population in USA respectively, Nigeria has one mega voltage radiotherapy machine per 60 million population [8].

\section{Knowledge}

Lack of knowledge of the need for screening test for cancer and the need for orthodox care is one of the major factors affecting the management of cancer in developing countries. A good number of Nigerian is largely unaware of the need to screen for cancer or of the improved treatment outcomes if cancer is detected early. Public awareness was probably more effective than the staff training as the staff never stayed long in the area before getting transferred. About sixty percent $(60 \%)$ of Nigerians do not seek orthodox medical care and over $70 \%$ do not have good knowledge of the dangers of untreated or poorly treated diseases (vanguard news 2012). Although, cancer has been described as a killer disease, experts say when detected early, patients 
diagnosed with these cancers may be cured. Unfortunately, the health seeking behaviour of Nigerians has continued to hinder successful treatment of cancer (Prof. Onyebuchi Chukwu).

\section{Shortage of health professional}

According to WHO 2006, health care professionals are often attracted by better paying jobs in cities or in well-funded HIV/AIDS programs at the detriment of rural cancer screening/early detection programs. The few qualified health professionals, who have been trained in more advanced cancer diagnosis and treatment, are often offered better paying jobs abroad and they leave health services in their home countries. Report from the technical adviser for the proposed international cancer center, Prof. Francis Durosinmi-Etti said that trained personnel for multidisciplinary cancer care maintenance and management are also inadequate in Nigeria.

\section{Access to drugs}

Cancer drugs are largely inaccessible. Access to cancer drugs is still limited or nonexistent for most cancer patients in developing countries and cancer is thus a death sentence for most people in these countries. Today, both treatment and diagnostics for cancer are expensive and difficult to obtain in LMICs. The costs of many targeted therapy drugs are very high (UICC) [5]. In Hong Kong the monthly cost of Gefitinib and Erlotinib, both used for non-small-cell lung carcinoma, is HKD 14 000 (US\$1806) and HKD 18000 (US\$2322), respectively, per month per patient [9].

In Nigeria for instance there are no cancer drugs or the little available are reserved for the political class and their relatives. Where the cancer drugs are seen, the prices of these and other therapies put them beyond the reach of public health systems in the country. Cancer drugs on the WHO list of essential drugs, which are low cost but effective cancer drugs, should be made available in developing countries based on public health priorities [10-13].

\section{Poor health system}

The few health facilities in LMIC that are capable of cancer diagnosis and treatment are usually inaccessible to poor, rural populations. As a result, most people receive little or no medical attention. We need a public health approach that is tailored to local conditions, an approach that integrates early detection, earlier diagnosis of cancer, effective treatment, and palliative care with other services in ways that strengthen health systems as at all levels. Health systems of developing countries, which are already struggling to cope with the AIDS epidemic, are illprepared to deal with this new and rapidly growing challenge. This could be confirmed by the fact that Nigeria managed to establish the first cancer care centre in 2009 by the then wife of president, Hajiya Tura Yaradua. The center was supposed to be the first in Africa. The center is presently ill equipped and poorly staffed if at there are professional caregivers there. This is to tell you how bad the situation is in Nigeria and Africa at large. Our leaders rarely give attention to this pandemic condition which is killing our poor masses on daily and weekly basis. Nigeria health system does not receive enough financial support for cancer care as compared to other areas like HIV/AIDS. Only 5\% of global resources devoted to cancer are spent in developing countries [6], and cancer control is conspicuously absent from the internationally agreed Millennium Development Goals [7].

\section{Recommendation}

- The Government of developing countries including Nigeria should place high priority on cancer and allot more percentage of her annual health budget to cancer care, screening, prevention, and treatment.

- International agency should please pay attention to the issues of cancer in developing countries through establishment of more screening and treatment centers.

- Public awareness about cancer should be given attention just as it was done in the earlier days of HIV/AIDS. This would help correct health seeking behavior of the citizenry which contributed to failure in treatment of cancers.

- Studies should be sponsored by both government and agencies in cancer as to obtain more statistics on the prevalence and treatment.

- Drugs for cancer treatment should be subsidized as in the case of HIV/AIDS to make it both affordable and accessible.

\section{Conclusion}

Currently in Nigeria, cancer of all types is common. Not any week or month has passed that a Nigerian did not die of cancer and cancer related causes. Hundreds of thousands are dying silently. Not much appears to have been done to stem the tide of deaths. Since 2009 when the first international cancer centre was built in Abuja which is currently non-functional, nothing else has been done in Africa to challenge the devastating effect of cancer in the continent. From the review, so far one would see that incidence of cancer in Nigeria is on the increase yet no one really cares. The poor masses are left to suffer and die of preventable and curable infirmity like cancer. People are not aware of the dangers, trained medical personnel are quite scarce, dedicated cancer centers are not available and where they are, they are ill equipped, no screening center in the whole country, diagnostic centers are limited to very few private owners which the poor masses cannot afford, cancer drugs are both inaccessible and expensive among others. This is the state of cancer in Nigeria which is not too different from other African countries.

\section{References}

1. Can Treat International (2010) Scaling up cancer diagnosis and treatment in developing countries: What can we learn from the HIVIAIDS epidemic? Ann oncol 21: 680-682

2. American cancer society (2010) Global cancer facts and figures. Atlanta GA.

3. Ngoma T (2006) World Health Organization cancer priorities in developing countries. Ann Oncol 17 (Suppl 8): viii9-viii14.

4. Huerta E, Grey N (2007) Cancer control opportunities in low-middle income countries. Cancer J Clin 57: 72-74.

5. UICC (2008) The world cancer declaration: A call to action from the global cancer community. International Union Against Cancer. Geneva.

6. Samei M, Rosenthal MD, Kinley D (2010) No time to lose. IAEA Bull 47: 1.

7. WHO (2006) The World Health Report 2006: Working together for Health Geneva.

8. UNAIDS (2008) Report on the global HIVIAIDS epidemic. Geneva.

9. Berkman A, Garcia J, Muñoz-Laboy M, Paiva V, Parker R (2005) A critical analysis of the Brazilian response to HIVIAIDS: Lessons learned for controlling and mitigating the epidemic in developing countries. Am J Public Health 95: 1162-1172.

10. UICC (2009) Access to cancer drugs. A UICC position paper, revision. International union against cancer (UICC), Geneva.

11. Sing-hung LO (2007) Hormonal therapy and targeted therapy in palliative cancer care. Palliative Care 4th Hong Kong Symposium, HKSPM News Lett 14-17.

12. Gerber D (2008) Targeted therapies: A new generation of cancer treatments Am Fam Physician 77: 311-319

13. Chinyera A (2009) Nigeria's first cancer center takes off. Vanguard news. 